\title{
Balkanologie
}

Balkanologie Revue d'études pluridisciplinaires

Vol. X, $n^{\circ} 1-2 \mid 2008$

Volume $X$ Numéro 1-2

\section{Egidio Ivetic, Le guerre balcaniche}

il Mulino Universale Paperbacks, Bologna, 2006

Joëlle Dalègre

\section{CpenEdition}

Journals

Édition électronique

URL : http://journals.openedition.org/balkanologie/416

DOI : 10.4000/balkanologie.416

ISSN : 1965-0582

Éditeur

Association française d'études sur les Balkans (Afebalk)

Référence électronique

Joëlle Dalègre, «Egidio Ivetic, Le guerre balcaniche », Balkanologie [En ligne], Vol. X, n 1-2 | 2008, mis en ligne le 03 avril 2008, consulté le 17 décembre 2020. URL : http://journals.openedition.org/

balkanologie/416 ; DOI : https://doi.org/10.4000/balkanologie.416

Ce document a été généré automatiquement le 17 décembre 2020.

(c) Tous droits réservés 


\title{
Egidio Ivetic, Le guerre balcaniche
}

\author{
il Mulino Universale Paperbacks, Bologna, 2006
}

\section{Joëlle Dalègre}

1 Ce petit livre compact et bien informé d'Egidio Ivetic, professeur d'histoire de l'Europe Orientale à l'Université de Padoue, - 163 pages de texte et 26 pages d'index et d'une riche bibliographie mise à jour - nous dresse un bilan des connaissances diplomatiques et militaires actuelles sur les guerres balkaniques. Cinq chapitres, de 1878 à 1913, exposent les grandes manœuvres diplomatiques, les ambitions et les tensions qui concernent toute la région (chapitres 1 et 2) puis les conflits eux-mêmes, dans les chapitres 3 et 4 . Le 5ème chapitre est capital car, ne se limitant pas au bilan humain, politique et diplomatique, il indique le but réel de l'auteur, sortir d'une histoire balkanique découpée par Etats et respectant les mythes nationalistes des uns et des autres pour tenter une démarche globale et plus « historique ».

2 En effet qu'est-ce qui distingue cet ouvrage de ceux qui existent déjà sur le sujet?

3 - son aspect synthétique dans un format limité et un style accessible,

4 - un souci de faire comprendre le monde balkanique actuel pour lequel ces guerres ont été un événement fondamental qui reste bien présent, en le considérant dans son ensemble et non Etat par Etat,

5 - sa volonté de démythifier l'histoire balkanique. L'ouvrage ne plaira pas à tous dans la région car l'auteur insiste sur le fait que, quoi qu'en disent les histoires nationales, les habitants annexés par la Grèce, la Bulgarie, la Roumanie, la Serbie, etc., étaient loin d'être tous Grecs, Bulgares, Roumains ou Serbes... qu'il n'y avait pas toujours "libération nationale», que les paysans musulmans chassés n'étaient pas tous de « sauvages exploiteurs».

6 Il montre également le coup de tonnerre sans égal que furent ces guerres pour les habitants des Balkans. Soldats tués au combat ou par les épidémies, civils massacrés, populations errantes dur les routes, ces guerres n'étaient pas « propres".

7 Les Alliés balkaniques mobilisèrent près de 800000 hommes en 1912 soit autant que la Grande Armée napoléonienne, plus que la Prusse en 1870 ou la Russie en 1877 et 300 000 soldats ottomans étaient présents dans l'été 1912 en Turquie d'Europe (leurs 
effectifs doublèrent au fil des mois). Les chiffres sont très controversés, mais en adoptant la version "moyenne", on peut remarquer qu'un soldat sur 5 est mort et qu'un sur 3 a été blessé. Utilisant l'enquête de la Fondation Carnegie récemment rééditée, l'auteur insiste également sur l'ampleur des massacres de civils, massacres perpétrés majoritairement contre les musulmans-Turcs mais aussi entre chrétiens dont chacun cherchait à simplifier ethniquement le territoire gagné. Qu'il s'agisse d'armées, de bandes d'irréguliers, de représailles ou de vengeances de voisinage, d'innombrables villages sont incendiés, les femmes violées, les hommes torturés ou exécutés, et plus de 600000 personnes au total ont fui leur maison. Drames humains, ruines innombrables, crise financière des Etats, ces guerres ont inauguré une période de désottomanisation accélérée et restent une étape capitale pour chacun des Etats de la région.

8 En conclusion un livre à lire si on cherche une bonne synthèse accessible et informée.

\section{AUTEUR}

JOËLLE DALÈGRE

INALCO 